\title{
Serotonin Transporter Binding in the Diencephalon Is Reduced in Insulin-Resistant Obese Humans
}

\author{
Ruth I. Versteeg ${ }^{a}$ Karin E. Koopman ${ }^{a}$ Jan Booij $^{b}$ Mariëtte T. Ackermans ${ }^{c}$ \\ Unga A. Unmehopa ${ }^{a}$ Eric Fliers ${ }^{a}$ Susanne E. la Fleur ${ }^{a}$ Mireille J. Serlie ${ }^{a}$ \\ Departments of ${ }^{a}$ Endocrinology and Metabolism, ${ }^{b}$ Nuclear Medicine, and ${ }^{c}$ Clinical Chemistry, Laboratory of \\ Endocrinology, Academic Medical Center, University of Amsterdam, Amsterdam, The Netherlands
}

\section{Key Words}

Dopamine transporter · Human imaging $\cdot$ Insulin resistance $\cdot$ Obesity $\cdot$ Serotonin transporter

Abstract
Background: Altered brain dopaminergic and serotonergic
pathways have been shown in obese rodents and humans,
but it is unknown whether this is related to obesity per se or
to the metabolic derangements associated with obesity. Methods: We performed a case-control study in insulin-sensitive obese (ISO) and insulin-resistant obese (IRO) subjects $(n=12)$ and age-matched lean controls $(n=8)$ and measured serotonin transporter (SERT) binding in the whole diencephalon and specifically in the hypothalamus, as well as dopamine transporter (DAT) binding in the striatum using ${ }^{123} \mathrm{I}-$ FP-CIT single-photon emission computed tomography. We assessed insulin sensitivity using the homeostatic model assessment of insulin resistance. Results: BMI did not differ between the IRO and ISO subjects. SERT binding in the diencephalon was significantly lower in IRO than in ISO subjects, but was not different between lean and obese subjects. SERT binding in the hypothalamus tended to be reduced in obese versus lean subjects, but was not different between IRO and

\section{KARGER}

E-Mail karger@karger.com www.karger.com/nen
C) 2016 The Author(s)

Published by S. Karger AG, Basel

Karger

0 pen access

This article is licensed under the Creative Commons AttributionNonCommercial-NoDerivatives 4.0 International License (CC BYNC-ND) (http://www.karger.com/Services/OpenAccessLicense). Usage and distribution for commercial purposes as well as any distribution of modified material requires written permission.
ISO subjects. Striatal DAT binding was similar between lean and obese subjects as well as between ISO and IRO subjects. Conclusions: We conclude that SERT binding in the diencephalon is reduced in insulin-resistant subjects independently of body weight, while hypothalamic SERT binding tends to be lower in obesity, with no difference between insulin-resistant and insulin-sensitive subjects. This suggests that the metabolic perturbations associated with obesity independently affect SERT binding within the diencephalon.

$$
\begin{aligned}
& \text { @ } 2016 \text { The Author(s) } \\
& \text { Published by S. Karger AG, Basel }
\end{aligned}
$$

\section{Introduction}

Serotonin is a monoamine neurotransmitter involved in the regulation of food intake and body weight [1], and in rodent studies altered brain serotonergic pathways have been linked to obesity. Neurochemical serotonin depletion in the rodent brain results in obesity and hyperphagia [2], and inversely infusion of serotonin into the

R.I. Versteeg and K.E. Koopman as well as S.E. la Fleur and M.J. Serlie contributed equally to this work. 
hypothalamus decreases body weight in Zucker rats [3]. Pharmacological studies in humans also point towards a role for the serotonin system in body weight regulation [4] since lorcaserin, a serotonin-2C receptor agonist, induces weight loss [5], and short-term use of selective serotonin reuptake inhibitors (SSRIs), which inhibit reuptake of serotonin via the serotonin transporter (SERT), also reduces body weight [4]. This suggests that in humans an increase in serotonergic signaling may be favorable for body weight management. In line with this, SERT binding in subcortical regions (caudate-putamen-thalamus) is inversely associated with BMI [6], and we recently showed reduced SERT immunostaining in the hypothalamic infundibular nucleus in postmortem tissue of overweight subjects [7]. Moreover, in the cerebrospinal fluid of obese women, serotonin and its metabolites were lower compared to lean controls [8]. Additionally, several studies point towards a regulatory role of central serotonergic signaling in glucose metabolism. Mice lacking the serotonin-2C receptor in proopiomelanocortin neurons have normal body weight but exhibit hyperglycemia, hyperinsulinemia, and insulin resistance [9], and SERTdeficient mice are hyperglycemic and hyperinsulinemic and have reduced insulin signaling in the liver prior to the occurrence of obesity [10]. In nondiabetic individuals, short-term treatment with SSRIs decreases fasting blood glucose levels [11], and SERT polymorphisms are linked to the occurrence of diabetes [12]. Together these studies suggest a link between serotonergic signaling and body weight regulation as well as a body weight-independent effect on glucose metabolism.

In addition to the diencephalic serotonergic system, striatal dopamine has been associated with body weight and glucose metabolism. Obese subjects have lower striatal dopamine $\mathrm{D} 2 / 3$ receptor $(\mathrm{D} 2 / 3 \mathrm{R})$ binding availability [13], and striatal D2/3R binding is associated with insulin sensitivity [14]. Additionally, D2R knockout mice have a blunted insulin response and are glucose-intolerant [15]. Increasing dopaminergic signaling using the dopamine receptor agonist bromocriptine in rodents and humans improves glucose metabolism $[16,17]$, and in obese rodents this is accompanied by an increase in striatal dopamine transporter (DAT) expression [18].

We aimed to investigate whether SERT binding in the diencephalon, and also specifically within the hypothalamus, as well as DAT binding in the striatum, measured with ${ }^{123} \mathrm{I}$-FP-CIT single-photon emission computed tomography (SPECT), is different between lean, insulin-resistant obese (IRO), and insulin-sensitive obese (ISO) humans.

\section{Methods}

\section{Subjects}

We included 12 obese subjects (10 women and 2 men; mean age $31.7 \pm 8.9$ years; mean BMI $36.6 \pm 4.4$ ) and 8 age-matched lean controls (all female; mean age $30.9 \pm 10.5$ years; mean BMI $21.3 \pm$ 1.3). All women were premenopausal and measurements were performed in the follicular phase of the menstrual cycle. Participants were in self-reported good health, had normal liver, renal, and thyroid function, did not smoke, and did not use any medication. In addition, all subjects had had a self-reported stable weight during 3 months prior to inclusion. A 75-gram glucose tolerance test was performed to exclude undiagnosed diabetes [19]. Substance abusers, shift workers, and subjects with a history of psychiatric or eating disorders (e.g. binge eating, restraint eating) were excluded, as were pregnant women. A pregnancy test was performed upon inclusion. The study protocol was approved by the institutional review board of the Academic Medical Center of the University of Amsterdam and conducted according to the Declaration of Helsinki of October 2008. Written informed consent was received from all participants after explanation of the nature of the study.

\section{Imaging of the SERT and the DAT}

Each participant underwent SPECT imaging with the radioligand ${ }^{123}$ I-FP-CIT (DaTSCAN). A total dose of $115 \mathrm{MBq}$ (range $110-120 \mathrm{MBq}$; specific activity $>750 \mathrm{MBq} / \mathrm{nmol}$; radiochemical purity $>98 \%$, produced according to the GMP criteria at GE Healthcare, Eindhoven, The Netherlands) was administered intravenously. This tracer can be used to image striatal DAT and extrastriatal SERT binding. SERT and DAT binding can be visualized and quantified adequately in the diencephalon [(hypo)thalamic region] and striatum 2 and $3 \mathrm{~h}$ after bolus injection, respectively, as described previously [20]. Participants were scanned at 10:30 a.m. ( $2 \mathrm{~h}$ after injection of the radiotracer) and at 11:30 a.m. (3 h after injection) after an overnight fast. Each participant was pretreated with potassium iodide to block thyroid uptake of free radioactive iodide. SPECT imaging was performed using a 12detector, single-slice brain-dedicated scanner (Neurofocus 810; Strichman Medical Equipment, Cleveland, Ohio, USA) using an acquisition protocol as described previously with slight modifications (interslice distance $5 \mathrm{~mm}$; acquisition time $210 \mathrm{~s} /$ slice) [20]. All scans were reconstructed in $3 \mathrm{D}$ mode and corrected for attenuation.

$M R I$

A T1-weighted MRI scan of the brain was performed on each individual for anatomical reference on a 3.0T Philips Interna scanner (Philips Healthcare, Best, The Netherlands) with a standard head coil.

\section{Image Analysis}

In the first analysis, a region of interest (ROI) analysis was performed to determine specific binding in the striatum, the whole diencephalon (which includes the thalamus, the subthalamus, the hypothalamus, and the epithalamus), and the hypothalamus. A ROI analysis using fixed ROIs was performed by one well-trained researcher (K.E.K.) as described previously [21]. Briefly, the four consecutive slices with the highest binding were selected to assess binding to DAT ( $3 \mathrm{~h}$ after injection) and SERT ( $2 \mathrm{~h}$ after injection). Activity in the cerebellum (3 consecutive slices) was assumed to
142

Neuroendocrinology 2017;105:141-149

DOI: $10.1159 / 000450549$
Versteeg/Koopman/Booij/Ackermans/ Unmehopa/Fliers/la Fleur/Serlie 


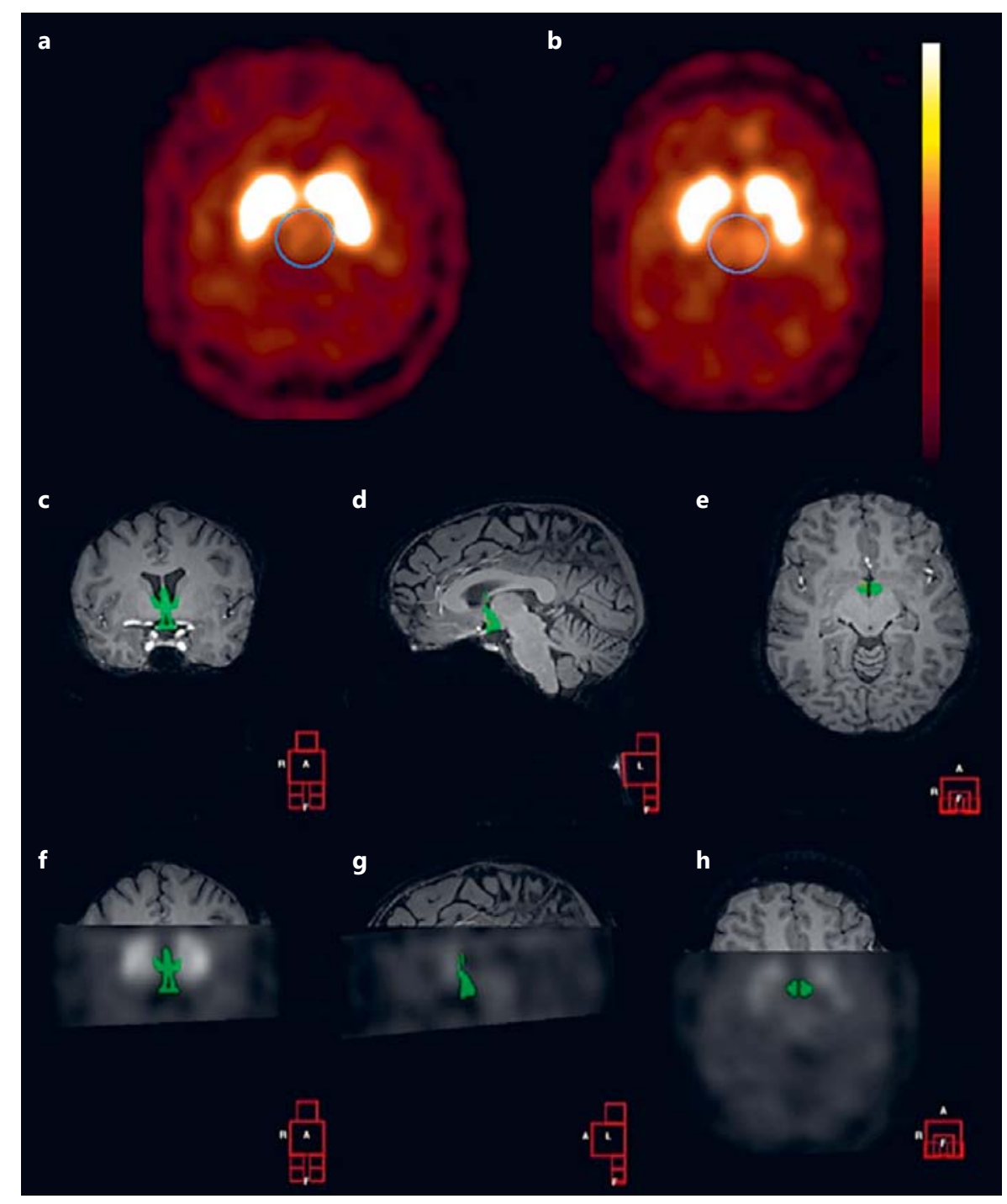

Fig. 1. Example of SERT binding. a, b Transverse SERT binding in the diencephalon of a lean (a) and IRO (b) subject. c-e ROI manually drawn on an individual coronal (c), sagittal (d), and transverse (e) MRI for assessment of hypothalamic SERT binding. f-h Coronal (f), sagittal (g), and transverse (h) co-registered SPECT and MRI image showing manually drawn ROI (hypothalamus).

represent nondisplaceable binding (nonspecific binding and free radioactivity). A specific to nonspecific binding ratio (SNS-BR) was calculated as (ROI-binding - cerebellar binding) / cerebellar binding, which was used as the outcome measure (binding potential). Representative scans with high and low diencephalic SERT binding are shown in figure $1 \mathrm{a}$ and $\mathrm{b}$.

In a second analysis, SERT binding in the hypothalamus was assessed using manually drawn ROIs on individual MRIs as described previously [22]. We used these manually drawn ROIs because it is not possible to identify the hypothalamus on SPECT images due to the limited spatial resolution. Consequently, ROIs for the hypothalamus and cerebellum were manually drawn on the T1-weighted MRI from each subject using a self-developed software [23] (an example is shown in fig. 1c-h). MRI data were missing from 1 lean and 1 IRO female subject due to technical problems. The SPECT scan and individual T1-weighted MRI scan were matched in all three $(\mathrm{x}, \mathrm{y}, \mathrm{z})$ planes for each subject by using the same software. The accuracy of registration was improved by com- paring (triangulation) co-registration of the T1-weighted MRI scan with the individual SPECT scans acquired at both time points, respectively. The individual T1-weighted MRI scan was registered to both SPECT scans to validate consistency and estimate the registration uncertainty. After matching, the mean amount of radioactivity/voxel in the hypothalamus was determined, and activity in the cerebellum (excluding vermis) was used to represent nonspecific binding. Finally, similar to the first analysis, an SNS-BR was calculated as (hypothalamic binding - cerebellar-binding) / cerebellar-binding.

\section{Laboratory Analysis}

Plasma glucose concentrations were measured with the glucose oxidase method using a Biosen C-line plus glucose analyzer (EKF Diagnostics, Barleben/Magedeburg, Germany). Insulin and cortisol were both measured on an IMMULITE 2000 system (Siemens Healthcare Diagnostics B.V., Breda, The Netherlands). Cortisol was measured with a chemiluminescent immunoassay (intra-as- 
Table 1. Baseline characteristics of the study participants

\begin{tabular}{|c|c|c|c|c|c|c|c|c|c|c|}
\hline & \multirow[t]{2}{*}{ Lean } & \multirow[t]{2}{*}{ Obese } & \multirow[t]{2}{*}{$\mathrm{p}$} & \multirow[t]{2}{*}{ ISO } & \multirow[t]{2}{*}{ IRO } & \multicolumn{2}{|c|}{ ANOVA } & \multicolumn{3}{|c|}{ Post hoc } \\
\hline & & & & & & $\mathrm{p}$ & $\mathrm{F}$ & $\begin{array}{l}\text { ISO vs. } \\
\text { IRO }\end{array}$ & $\begin{array}{l}\text { IRO vs. } \\
\text { lean }\end{array}$ & $\begin{array}{l}\text { ISO vs. } \\
\text { lean }\end{array}$ \\
\hline Number & 8 & 12 & & 6 & 6 & & & & & \\
\hline $\mathrm{M}: \mathrm{F}$ ratio & $0: 8$ & $2: 10$ & & $1: 5$ & $1: 5$ & & & & & \\
\hline Age, years & $30.9 \pm 10.5$ & $31.3 \pm 8.8$ & 0.917 & $34.7 \pm 9.9$ & $28.0 \pm 6.6$ & 0.477 & 0.77 & & & \\
\hline $\mathrm{BMI}$ & $21.3 \pm 1.3$ & $36.6 \pm 4.6$ & $<0.001$ & $34.9 \pm 3.8$ & $38.3 \pm 5.1$ & $<0.001$ & 39.10 & 1 & $<0.001$ & $<0.001$ \\
\hline Glucose, $\mathrm{mmol} / \mathrm{l}$ & $4.4 \pm 0.4$ & $4.9 \pm 0.4$ & 0.008 & $4.8 \pm 0.3$ & $5.0 \pm 0.4$ & 0.019 & 5.04 & 0.882 & 0.019 & 0.206 \\
\hline Insulin, $\mathrm{pmol} / \mathrm{l}$ & $23 \pm 13$ & $106 \pm 128$ & 0.046 & $29 \pm 11$ & $184 \pm 146$ & 0.003 & 8.21 & 0.011 & 0.005 & 1 \\
\hline C-peptide, $\mathrm{mg} / \mathrm{ml}$ & $499 \pm 102$ & $873 \pm 402$ & 0.009 & $655 \pm 83$ & $1,092 \pm 484$ & 0.003 & 8.19 & 0.042 & 0.003 & 0.926 \\
\hline Cortisol, nmol/l & $468 \pm 242$ & $342 \pm 157$ & 0.172 & $271 \pm 85$ & $412 \pm 188$ & 0.185 & 1.87 & & & \\
\hline Glucagon, ng/l & $73 \pm 20$ & $94 \pm 31$ & 0.114 & $95 \pm 36$ & $92 \pm 28$ & 0.291 & 1.33 & & & \\
\hline HOMA-IR & $0.7 \pm 0.5$ & $3.4 \pm 4.2$ & 0.045 & $0.9 \pm 0.3$ & $6.0 \pm 4.8$ & 0.003 & 8.36 & 0.011 & 0.005 & 1 \\
\hline
\end{tabular}

Data are presented as mean $\pm \mathrm{SD}$.

say variation: 7-8\%; total assay variation: $7-8 \%$; detection limit: $50 \mathrm{nM}$ ). Insulin was measured with a chemiluminescent immunometric assay (intra-assay variation: $3-6 \%$; total assay variation: $4 \%$; detection limit: $15 \mathrm{pM}$ ). C-peptide levels were measured with a ${ }^{125} \mathrm{I}$ radioimmunoassay (Merck Millipore, St. Charles, Mo., USA) (intra-assay variation: 6-9\%; total assay variation: $7-11 \%$; detection limit: $50 \mathrm{pM})$. Glucagon was measured with the ${ }^{125} \mathrm{I}$ radioimmunoassay (Merck Millipore) (intra-assay variation: 9-10\%; total assay variation: $5-7 \%$; detection limit: $15 \mathrm{ng} / \mathrm{l})$.

\section{Insulin Sensitivity}

We used the homeostatic model assessment of insulin resistance (HOMA-IR) to assess insulin sensitivity. The HOMA-IR is calculated from fasting plasma insulin and glucose and has been shown to correlate with clamp-derived peripheral glucose disposal rates [24]:

$$
\text { HOMA-IR }=\frac{(\text { fasting plasma glucose } \times(\text { fasting plasma insulin } \times 6.945))}{22.5} .
$$

To determine whether subjects were insulin-resistant or insulinsensitive, we used a cutoff value for insulin resistance $>2.2[25]$ and fasting insulin $>73.5 \mathrm{pmol} / \mathrm{l}[26]$.

\section{Statistics}

All data were analyzed using SPSS for Windows, version 20.0 (SPSS Inc., Chicago, Ill., USA). Data were tested for normality. To compare data between the lean and obese group, we used Student's $t$ test. We used one-way ANOVA and a post hoc Bonferroni test to evaluate data between the lean, ISO, and IRO groups. Within the obese group, ANCOVA was used with BMI as a covariate. Pearson correlation coefficients were calculated to investigate the relationship between SNS-BR and BMI as well as between SNS-BR and insulin sensitivity. For all analyses, $\mathrm{p}<0.05$ was considered statistically significant and $\mathrm{p}<0.1$ was considered a trend. Sample size calculation was based on a previous study showing that diencephalic SERT binding in lean subjects was $0.51 \pm 0.17$ [20]. To detect a difference with a significance level $\alpha=0.05$, power $=80 \%$, vari- ance of means $=0.029$, and common standard deviation $=0.17$, we needed 5 subjects per group (calculated with the nQuery Advisor 7.0 software).

\section{Results}

\section{Lean versus Obese Subjects}

The baseline characteristics of the study participants are presented in table 1 . As expected, the obese subjects had higher HOMA-IR, fasting plasma glucose, insulin, and C-peptide concentrations compared to the lean controls. SERT binding in the diencephalon was not different between lean and obese subjects $(0.89 \pm 0.32$ vs. $0.71 \pm$ $0.33, \mathrm{p}=0.25$ ) (fig. $2 \mathrm{a}$ ). Since the hypothalamus plays a major role in the regulation of glucose metabolism and food intake [27, 28] and reduced serotonergic signaling might contribute to body weight and insulin sensitivity, we studied SERT binding specifically within the hypothalamus. Hypothalamic SERT binding tended to be lower in obese subjects compared to lean subjects $(1.12 \pm 0.73$ vs. $0.62 \pm 0.28, \mathrm{p}=0.059$ ) (fig. $2 \mathrm{~b}$ ). Striatal DAT binding did not differ between the lean and obese subjects (4.59 \pm 1.08 vs. $4.99 \pm 1.18, \mathrm{p}=0.46$ ) (fig. $2 \mathrm{c}$ ). BMI did not correlate with SERT and DAT binding within the obese or lean subjects (data not shown).

\section{ISO versus IRO Subjects}

Since central serotonergic signaling might have independent effects on glucose metabolism or vice versa, we studied a body weight-independent effect of insulin sen- 


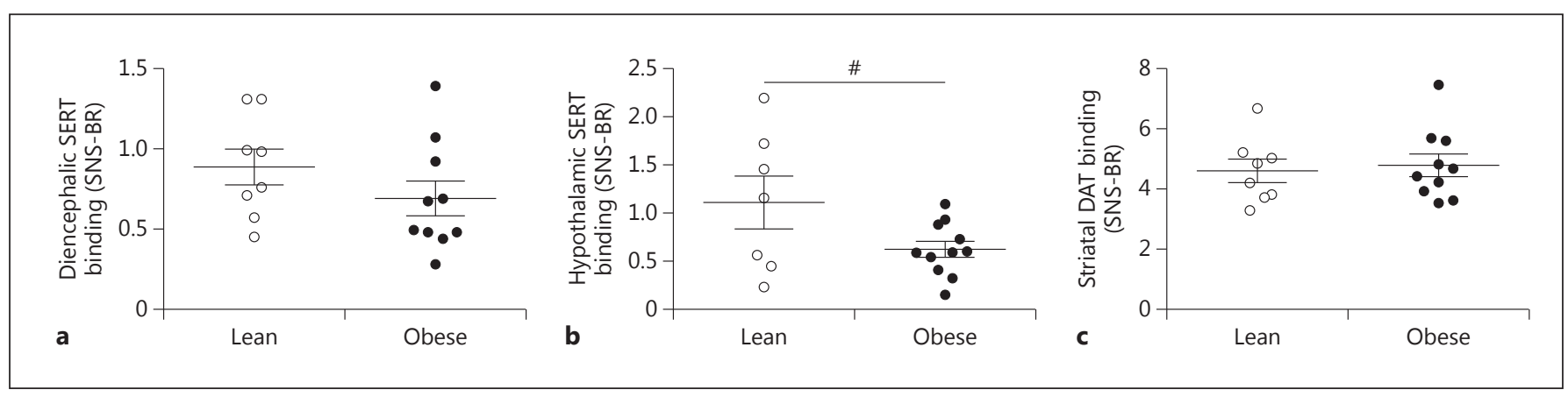

Fig. 2. SERT and DAT binding in lean and obese subjects. a Diencephalic SERT binding. b Hypothalamic SERT binding. c Striatal DAT binding. Data are presented as mean \pm SEM. ${ }^{\#} \mathrm{p}=0.059$.

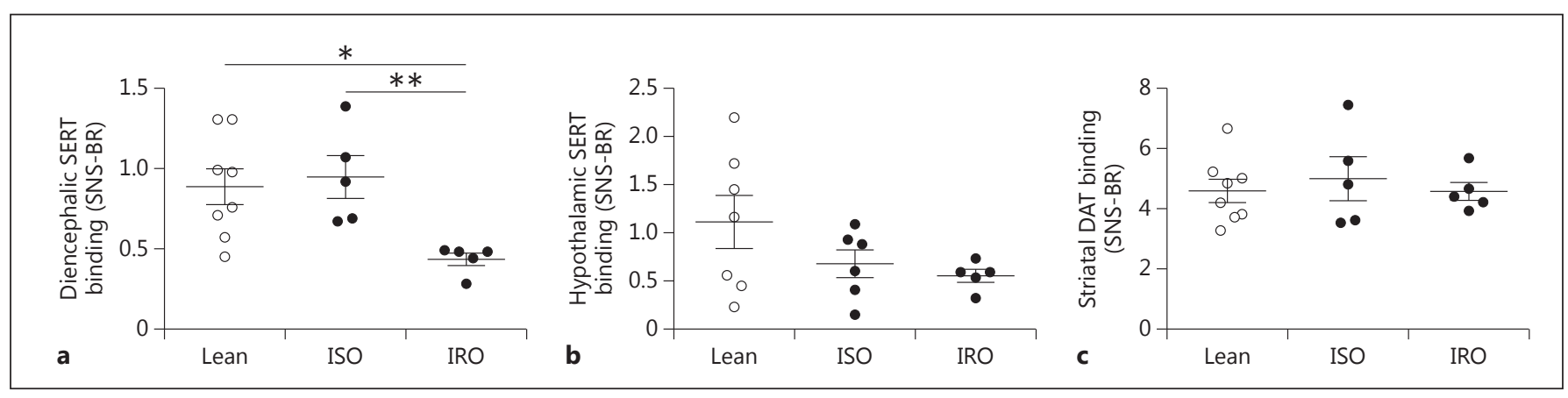

Fig. 3. SERT and DAT binding in lean versus ISO and IRO subjects. a Diencephalic SERT binding. b Hypothalamic SERT binding (lean $\mathrm{n}=7$, IRO $\mathrm{n}=5$ ). c Striatal DAT binding. Data are presented as mean \pm SEM. ${ }^{*} \mathrm{p}<0.05$ (one-way ANOVA), ${ }^{* *} \mathrm{p}<0.01$ (ANCOVA).

sitivity on SERT and DAT and analyzed subjects with low and high insulin sensitivity separately. We divided the obese group into an insulin-sensitive and an insulin-resistant group. BMI did not differ between ISO and IRO subjects while insulin, glucose, and C-peptide concentrations were higher in IRO subjects. HOMA-IR was not significantly different between the insulin-sensitive group and the lean controls. Fasting plasma glucagon and cortisol concentrations were not different between the three groups (table 1). We found that IRO subjects had significantly lower diencephalic SERT binding compared to ISO $(0.45 \pm 0.09$ vs. $0.97 \pm 0.27, \mathrm{p}=0.009)$ and lean subjects $(0.45 \pm 0.09$ vs. $0.89 \pm 0.32, \mathrm{p}=0.019)$, while there was no difference between lean and ISO subjects. ANCOVA revealed a significant effect on diencephalic SERT availability between ISO and IRO subjects, independent of BMI (adjusted mean $0.56 \pm 0.14$ vs. $1.08 \pm 0.15, p=0.009$ ) (fig. 3a). Hypothalamic SERT binding did not differ between lean, IRO, and ISO subjects (ANOVA, F $=2.04$, $\mathrm{p}=0.17$ ) (fig. 3b). Moreover, no differences in striatal DAT binding were found between lean, ISO, and IRO subjects (ANOVA, $\mathrm{F}=0.33, \mathrm{p}=0.72$ ) (fig. $3 \mathrm{c}$ ). Insulin sensitivity neither correlated to SERT nor DAT binding within the obese or lean subjects.

\section{Discussion}

We here showed lower diencephalic SERT binding in insulin-resistant subjects compared to lean and equally obese but insulin-sensitive subjects. In addition, we found a trend towards lower SERT binding in the hypothalamus of obese subjects. Striatal DAT binding was neither different between the lean and obese group nor between the IRO and ISO group.

To the best of our knowledge, this is the first study examining SERT binding in the human diencephalon in relation to insulin resistance in obesity. Previous imaging 
studies showed a negative correlation between BMI and diencephalic SERT binding in some [6] but not all [2931] studies, and data on insulin sensitivity were not reported.

Whether lower binding of SERT in our subjects is associated with reduced or increased synaptic serotonin is unknown. Acute inhibition of SERT function results in increased levels of extracellular serotonin [32], while chronic inhibition of SERT might result in decreased serotonergic signaling, given the detrimental long-term effects of SSRI use on food intake and body weight [33]. In line with this, obese humans have lower serotonin metabolites in the cerebrospinal fluid compared to lean controls [8]. Furthermore, SERT-deficient mice have decreased expression of brain serotonin-2A/C receptors, while overexpression results in increased brain serotonin-2A/C receptors [34], suggesting that prolonged reduction of SERT corresponds with lower serotonergic signaling. Moreover, a decrease in synaptic serotonin levels has been reported to reduce SERT density and mRNA levels in rats [35], which may reflect a compensatory mechanism to maintain sufficient serotonin levels in the synaptic cleft. Also, acute reduction in synaptic serotonin levels induced lower SERT binding in a positron emission tomography (PET) study in baboons, which is contrary to what is predicted by a competition model [36]. We therefore assume that a reduction in SERT binding reflects lower synaptic serotonin levels. Lower extracellular serotonin levels result in less inhibition of food intake and body weight gain [37] and could be either a cause or a consequence of obesity. Since diencephalic SERT binding was not different between ISO and lean subjects while SERT binding within the hypothalamus tended to be lower in all obese participants compared to the lean controls, lower extracellular serotonin, specifically within the hypothalamus, might contribute to the increased body weight in the obese group. Additionally, diet composition and pattern may have an independent effect on SERT binding, as we recently showed that in lean individuals a hypercaloric high-fat-high-sugar snacking diet reduces SERT binding in the diencephalon as assessed with ${ }^{123} \mathrm{I}-$ FP-CIT SPECT [38]. This is in line with previous data showing reduced serotonin concentrations in the hypothalamus after fat intake [39]. We did not assess dietary intake and therefore cannot rule out a diet-independent effect on SERT.

The underlying pathways explaining the relationship between insulin resistance and diencephalic SERT binding in humans remain speculative. We cannot distinguish between effects of insulin and/or glucose or other meta- bolic factors associated with insulin resistance, such as inflammatory proteins or adipokines, on SERT binding. Furthermore, reduced SERT and/or serotonin might directly affect insulin sensitivity. Studies in humans indicate an increased risk of diabetes in subjects on SSRIs [40], although this does not necessarily implicate a central mechanism, and modulation of serotonergic signaling by targeting the serotonin-2C receptor or SERT itself affects glucose metabolism $[4,5]$. Furthermore, SERT-deficient mice develop obesity and exhibit glucose intolerance and insulin resistance [10]. Moreover, manipulating central serotonergic activity affects glucose and insulin levels in rats, although the results are contradictory, as peripheral infusion of glucose and insulin leads to a decrease [41] or increase [42] in extracellular serotonin release, respectively. Based on the available data, we hypothesize that lower SERT in the diencephalon reduces serotonin signaling, which negatively affects glucose metabolism.

Studies on in vivo differences in hypothalamic SERT in obese humans are lacking, and although the available imaging techniques at present do not allow for studying specific hypothalamic nuclei as a result of limited resolution, our findings are in line with an earlier report in which we showed lower SERT immunostaining in the hypothalamic infundibular nucleus of overweight and obese subjects [7]. Lower serotonin signaling in the hypothalamus therefore might contribute to weight gain in humans. In contrast to the whole diencephalon, there was no difference in hypothalamic SERT binding between the insulin-resistant and insulin-sensitive group. This might indicate that the observed difference in diencephalic SERT binding between ISO and IRO is specific to a diencephalic region other than the hypothalamus. Scarce data show some potential areas of interest within the diencephalon besides the hypothalamus that might be related to peripheral glucose metabolism, including the thalamus and the epithalamus. However, the role of serotonin, in relation to glucose metabolism, is not known in these areas. Nonobese type 2 diabetic Goto-Kakizaki rats show decreased mRNA transcript levels of the pineal insulin receptors [43] and have lower serotonin and tryptophan levels in the pineal gland, which is part of the epithalamus [44]. Furthermore, a lower increase in glucose levels within the thalamus was found in response to plasma hyperglycemia in type 1 diabetic humans compared to nondiabetic humans [45], suggesting a role for circulating insulin, although frontal and temporal cerebral metabolites, measured using spectroscopy, were not different under hyperinsulinemic conditions in the thalamus between lean men with high versus low insulin sensitivity [46].
146

Neuroendocrinology 2017;105:141-149 DOI: $10.1159 / 000450549$
Versteeg/Koopman/Booij/Ackermans/ Unmehopa/Fliers/la Fleur/Serlie 
The currently used imaging tool does not have the spatial resolution to evaluate SERT binding in such small brain areas, and translational research in rodents is needed to study this in more detail.

In contrast to the findings on SERT, we did not find a difference in striatal DAT binding between lean and obese subjects or IRO and ISO subjects. Although a recent rodent study reported that both striatal DAT and D2R density are decreased in diet-induced obesity [47], our data are consistent with two recently published European multicenter ${ }^{123} \mathrm{I}$-FP-CIT SPECT studies in humans reporting no association between BMI and striatal DAT binding in lean and overweight humans $[48,49]$. Whereas DAT binding may not be affected by BMI in humans, we and others have previously reported on lower striatal dopamine D2/3R availability in obese compared to lean individuals [13], which suggests that lower D2/3R binding in obesity is not compensated by an increase in synaptic dopamine levels through a downregulation of DAT. Genetic factors might play an additional role in reduced striatal dopaminergic tone since adults with a polymorphism in the D2 receptor gene, associated with compromised striatal dopamine signaling, are at high risk of becoming obese [50].

Our study has some limitations. First, the majority of our subjects were premenopausal women and our results remain to be validated in different age groups. Second, we studied men and women, while gender differences have been observed for striatal DAT [51] and diencephalic SERT binding [52], but not for hypothalamic SERT binding [31]. However, analyses of our results on SERT and DAT did not change after excluding the male subjects. Third, we used a mathematical model to calculate insulin sensitivity, and although HOMA-IR correlates well with clamp-derived insulin sensitivity and therefore provides a good, commonly used, and less invasive alternative to hyperinsulinemic euglycemic clamps [24], we cannot distinguish between liver and muscle insulin resistance in relation to SERT. Finally, although we used a brain-ded- icated SPECT system, the presently used radiotracer ${ }^{123} \mathrm{I}$ FP-CIT is not selective as it binds in vivo to both SERT and DAT. Consequently, our results are in need of replication using a selective SERT tracer and PET.

In conclusion, SERT binding is reduced in the diencephalon of insulin-resistant versus equally obese insulin-sensitive subjects, showing a weight-independent effect on SERT binding. Within the hypothalamus, SERT binding tends to be reduced in obese compared to lean humans independent of insulin sensitivity. It remains to be studied which structure within the diencephalon shows lower SERT in the insulin-resistant state and whether interventions that increase SERT reduce insulin resistance or vice versa.

\section{Acknowledgments}

We wish to acknowledge our research assistant Martine van Vessem for her help with the oral glucose tolerance tests, and we thank Dr. J.M. Chou-Green of CG Scientific Editing for English editing. The study was funded by a PhD fellowship grant awarded by the AMC Executive Board. R.I. Versteeg was supported by STW OnTime (project No. 12189).

\section{Authors' Contributions}

All authors contributed significantly to the manuscript. K.E. Koopman and R.I. Versteeg collected and analyzed the data and drafted the manuscript. M.T. Ackermans and U.A. Unmehopa performed laboratory and imaging analyses and revised the manuscript. J. Booij, E. Fliers, S.E. la Fleur, and M.J. Serlie provided important intellectual input and revised the manuscript. All authors gave final approval of the version to be published.

\section{Disclosure Statement}

K.E. Koopman, R.I. Versteeg, E. Fliers, M.T. Ackermans, S.E. la Fleur, and M.J. Serlie have nothing to disclose. J. Booij is a consultant at GE Healthcare.

\section{References}

1 Lam DD, Garfield AS, Marston OJ, Shaw J, Heisler LK: Brain serotonin system in the coordination of food intake and body weight. Pharmacol Biochem Behav 2010;97:84-91.

2 Breisch ST, Zemlan FP, Hoebel BG: Hyperphagia and obesity following serotonin depletion by intraventricular p-chlorophenylalanine. Science 1976;192:382-385.

Serotonin Transporters in Obesity and Insulin Resistance
3 Fetissov SO, Meguid MM: Serotonin delivery into the ventromedial nucleus of the hypothalamus affects differently feeding pattern and body weight in obese and lean Zucker rats. Appetite 2010;54:346-353.

4 Halford JC, Harrold JA, Boyland EJ, Lawton CL, Blundell JE: Serotonergic drugs: effects on appetite expression and use for the treatment of obesity. Drugs 2007;67:27-55.
5 Colman E, Golden J, Roberts M, Egan A, Weaver J, Rosebraugh C: The FDA's assessment of two drugs for chronic weight management. N Engl J Med 2012;367:1577-1579.

6 Erritzoe D, Frokjaer VG, Haahr MT, Kalbitzer J, Svarer C, Holst KK, Hansen DL, Jernigan TL, Lehel S, Knudsen GM: Cerebral serotonin transporter binding is inversely related to body mass index. Neuroimage 2010;52:284-289. 
7 Borgers AJ, Koopman KE, Bisschop PH, Serlie MJ, Swaab DF, Fliers E, la Fleur SE, Alkemade A: Decreased serotonin transporter immunoreactivity in the human hypothalamic infundibular nucleus of overweight subjects. Front Neurosci 2014;8:106.

8 Strombom U, Krotkiewski M, Blennow K, Mansson JE, Ekman R, Bjorntorp P: The concentrations of monoamine metabolites and neuropeptides in the cerebrospinal fluid of obese women with different body fat distribution. Int J Obes Relat Metab Disord 1996;20: 361-368.

9 Berglund ED, Liu C, Sohn JW, Liu T, Kim MH, Lee CE, Vianna CR, Williams KW, Xu Y, Elmquist JK: Serotonin $2 \mathrm{C}$ receptors in proopiomelanocortin neurons regulate energy and glucose homeostasis. J Clin Invest 2013; 123:5061-5070.

10 Chen X, Margolis KJ, Gershon MD, Schwartz GJ, Sze JY: Reduced serotonin reuptake transporter (SERT) function causes insulin resistance and hepatic steatosis independent of food intake. PLoS One 2012;7:e32511.

11 Ghaeli P, Shahsavand E, Mesbahi M, Kamkar MZ, Sadeghi M, Dashti-Khavidaki S: Comparing the effects of 8-week treatment with fluoxetine and imipramine on fasting blood glucose of patients with major depressive disorder. J Clin Psychopharmacol 2004;24:386388

12 Iordanidou M, Tavridou A, Petridis I, Arvanitidis KI, Christakidis D, Vargemezis V, Manolopoulos VG: The serotonin transporter promoter polymorphism (5-HTTLPR) is associated with type 2 diabetes. Clin Chim Acta 2010;411:167-171.

13 Wang GJ, Volkow ND, Logan J, Pappas NR, Wong CT, Zhu W, Netusil N, Fowler JS: Brain dopamine and obesity. Lancet 2001;357:354357.

14 Dunn JP, Kessler RM, Feurer ID, Volkow ND, Patterson BW, Ansari MS, Li R, Marks-Shulman P, Abumrad NN: Relationship of dopamine type 2 receptor binding potential with fasting neuroendocrine hormones and insulin sensitivity in human obesity. Diabetes Care 2012;35:1105-1111.

15 Garcia-Tornadu I, Ornstein AM, ChamsonReig A, Wheeler MB, Hill DJ, Arany E, Rubinstein M, Becu-Villalobos D: Disruption of the dopamine D2 receptor impairs insulin secretion and causes glucose intolerance. Endocrinology 2010;151:1441-1450.

16 Defronzo RA: Bromocriptine: a sympatholytic, D2-dopamine agonist for the treatment of type 2 diabetes. Diabetes Care 2011;34:789794.

17 Luo S, Liang Y, Cincotta AH: Intracerebroventricular administration of bromocriptine ameliorates the insulin-resistant/glucose-intolerant state in hamsters. Neuroendocrinology 1999;69:160-166.

18 Davis LM, Michaelides M, Cheskin LJ, Moran TH, Aja S, Watkins PA, Pei Z, Contoreggi C, McCullough K, Hope B, Wang GJ, Volkow ND, Thanos PK: Bromocriptine administra- tion reduces hyperphagia and adiposity and differentially affects dopamine D2 receptor and transporter binding in leptin-receptordeficient Zucker rats and rats with diet-induced obesity. Neuroendocrinology 2009;89: 152-162.

19 American Diabetes Association: Diagnosis and classification of diabetes mellitus. Diabetes Care 2010;33(suppl 1):S62-S69.

20 Booij J, de Jong J, de Bruin K, Knol R, de Win MM, van Eck-Smit BL: Quantification of striatal dopamine transporters with ${ }^{123}$ I-FPCIT SPECT is influenced by the selective serotonin reuptake inhibitor paroxetine: a double-blind, placebo-controlled, crossover study in healthy control subjects. J Nucl Med 2007;48:359-366.

21 Booij J, Hemelaar TG, Speelman JD, de Bruin $\mathrm{K}$, Janssen AG, van Royen EA: One-day protocol for imaging of the nigrostriatal dopaminergic pathway in Parkinson's disease by [123I]FPCIT SPECT. J Nucl Med 1999;40: 753-761.

22 Borgers AJ, Alkemade A, Van de Giessen EM, Drent ML, Booij J, Bisschop PH, Fliers E: Imaging of serotonin transporters with [123I]FP-CIT SPECT in the human hypothalamus. EJNMMI Res 2013;3:34.

23 van Herk M, de Jaeger K, de Munck J, Hoogeman M, Meinders JPL, Zijp L: A delineation system for $\mathrm{N}$ modalities - software aspects (extended abstract). 13th ICCR, Heidelberg, Germany, pp 73-75.

24 Matthews DR, Hosker JP, Rudenski AS, Naylor BA, Treacher DF, Turner RC: Homeostasis model assessment: insulin resistance and beta-cell function from fasting plasma glucose and insulin concentrations in man. Diabetologia 1985;28:412-419.

25 Andersson DP, Wahrenberg H, Toft E, Qvisth V, Lofgren P, Hertel K, Leijonhufvud BM, Thorell A, Naslund E, Arner P: Waist circumference to assess reversal of insulin resistance following weight reduction after bariatric surgery: cohort and cross-sectional studies. Int J Obes (Lond) 2014;38:438-443.

26 ter Horst KW, Gilijamse PW, Koopman KE, de Weijer BA, Brands M, Kootte RS, Romijn JA, Ackermans MT, Nieuwdorp M, Soeters MR, Serlie MJ: Insulin resistance in obesity can be reliably identified from fasting plasma insulin. Int J Obes (Lond) 2015;39:17031709.

27 Xu Y, Berglund ED, Sohn JW, Holland WL, Chuang JC, Fukuda M, Rossi J, Williams KW, Jones JE, Zigman JM, Lowell BB, Scherer PE, Elmquist JK: 5-HT2CRs expressed by proopiomelanocortin neurons regulate insulin sensitivity in liver. Nat Neurosci 2010;13: 1457-1459.

28 Schwartz MW, Woods SC, Porte D Jr, Seeley RJ, Baskin DG: Central nervous system control of food intake. Nature 2000;404:661-671.

29 Koskela AK, Kaurijoki S, Pietilainen KH, Karhunen L, Pesonen U, Kuikka JT, Kaprio J, Rissanen A: Serotonin transporter binding and acquired obesity - an imaging study of mono- zygotic twin pairs. Physiol Behav 2008;93: 724-732.

30 Hesse S, van de Giessen E, Zientek F, Petroff D, Winter K, Dickson JC, Tossici-Bolt L, Sera T, Asenbaum S, Darcourt J, Akdemir UO, Knudsen GM, Nobili F, Pagani M, Vander Borght T, Van Laere K, Varrone A, Tatsch K, Sabri O, Booij J: Association of central serotonin transporter availability and body mass index in healthy Europeans. Eur Neuropsychopharmacol 2014;24:1240-1247.

31 Hesse S, Rullmann M, Luthardt J, Winter K, Hankir MK, Becker GA, Zientek F, Reissig G, Regenthal R, Drabe M, Schinke C, Bresch A, Arelin K, Lobsien D, Patt M, Meyer PM, Fasshauer M, Fenske WK, Bluher M, Stumvoll $\mathrm{M}$, Sabri O: Central serotonin transporter availability in highly obese individuals compared with non-obese controls: a [(11)C] DASB positron emission tomography study. Eur J Nucl Med Mol Imaging 2016;43:1096-1104.

32 Zhong H, Haddjeri N, Sanchez C: Escitalopram, an antidepressant with an allosteric effect at the serotonin transporter - a review of current understanding of its mechanism of action. Psychopharmacology (Berl) 2012;219: 1-13.

33 Fava M, Judge R, Hoog SL, Nilsson ME, Koke SC: Fluoxetine versus sertraline and paroxetine in major depressive disorder: changes in weight with long-term treatment. J Clin Psychiatry 2000;61:863-867.

34 Dawson N, Ferrington L, Lesch KP, Kelly PA: Cerebral metabolic responses to 5-HT2A/C receptor activation in mice with genetically modified serotonin transporter (SERT) expression. Eur Neuropsychopharmacol 2011; 21:117-128.

35 Linnet K, Koed K, Wiborg O, Gregersen N: Serotonin depletion decreases serotonin transporter mRNA levels in rat brain. Brain Res 1995;697:251-253.

36 Milak MS, Ogden RT, Vinocur DN, Van Heertum RL, Cooper TB, Mann JJ, Parsey RV: Effects of tryptophan depletion on the binding of [11C]-DASB to the serotonin transporter in baboons: response to acute serotonin deficiency. Biol Psychiatry 2005;57: 102-106.

37 Donovan MH, Tecott LH: Serotonin and the regulation of mammalian energy balance. Front Neurosci 2013;7:36.

38 Koopman KE, Booij J, Fliers E, Serlie MJ, la Fleur SE: Diet-induced changes in the Lean Brain: hypercaloric high-fat-high-sugar snacking decreases serotonin transporters in the human hypothalamic region. Mol Metab 2013;2:417-422.

39 Rouch C, Nicolaidis S, Orosco M: Determination, using microdialysis, of hypothalamic serotonin variations in response to different macronutrients. Physiol Behav 1999;65:653657.

40 Andersohn F, Schade R, Suissa S, Garbe E: Long-term use of antidepressants for depressive disorders and the risk of diabetes mellitus. Am J Psychiatry 2009;166:591-598. 
41 Orosco M, Nicolaidis S: Insulin and glucoseinduced changes in feeding and medial hypothalamic monoamines revealed by microdialysis in rats. Brain Res Bull 1994;33:289-297.

42 Orosco M, Rouch C, Gerozissis K: Activation of hypothalamic insulin by serotonin is the primary event of the insulin-serotonin interaction involved in the control of feeding. Brain Res 2000;872:64-70.

43 Peschke E, Frese T, Chankiewitz E, Peschke D, Preiss U, Schneyer U, Spessert R, Muhlbauer E: Diabetic Goto Kakizaki rats as well as type 2 diabetic patients show a decreased diurnal serum melatonin level and an increased pancreatic melatonin-receptor status. J Pineal Res 2006;40:135-143.

44 Frese T, Bach AG, Muhlbauer E, Ponicke K, Bromme HJ, Welp A, Peschke E: Pineal melatonin synthesis is decreased in type 2 diabetic Goto-Kakizaki rats. Life Sci 2009;85:526-533.

45 Heikkila O, Lundbom N, Timonen M, Groop $\mathrm{PH}$, Heikkinen S, Makimattila S: Evidence for abnormal glucose uptake or metabolism in thalamus during acute hyperglycaemia in type 1 diabetes - a 1H MRS study. Metab Brain Dis 2010;25:227-234.

46 Karczewska-Kupczewska M, Tarasow E, Nikolajuk A, Stefanowicz M, Matulewicz N,
Otziomek E, Gorska M, Straczkowski M, Kowalska I: The effect of insulin infusion on the metabolites in cerebral tissues assessed with proton magnetic resonance spectroscopy in young healthy subjects with high and low insulin sensitivity. Diabetes Care 2013;36: 2787-2793.

47 Hryhorczuk C, Florea M, Rodaros D, Poirier I, Daneault C, Des Rosiers C, Arvanitogiannis A, Alquier T, Fulton S: Dampened mesolimbic dopamine function and signaling by saturated but not monounsaturated dietary lipids. Neuropsychopharmacology 2016;41: 811-821.

48 van de Giessen E, Hesse S, Caan MW, Zientek F, Dickson JC, Tossici-Bolt L, Sera T, Asenbaum S, Guignard R, Akdemir UO, Knudsen GM, Nobili F, Pagani M, Vander Borght T, Van Laere K, Varrone A, Tatsch K, Booij J, Sabri O: No association between striatal dopamine transporter binding and body mass index: a multi-center European study in healthy volunteers. Neuroimage 2013;64:6167.

49 Thomsen G, Ziebell M, Jensen PS, da Cuhna-Bang S, Knudsen GM, Pinborg LH: No correlation between body mass index and striatal dopamine transporter availability in healthy volunteers using SPECT and [123I]PE2I. Obesity (Silver Spring) 2013;21: 1803-1806.

50 Stice E, Spoor S, Bohon C, Small DM: Relation between obesity and blunted striatal response to food is moderated by TaqIA A1 allele. Science 2008;322:449-452.

51 Varrone A, Dickson JC, Tossici-Bolt L, Sera T, Asenbaum S, Booij J, Kapucu OL, Kluge A, Knudsen GM, Koulibaly PM, Nobili F, Pagani M, Sabri O, Vander Borght T, Van Laere K, Tatsch K: European multicentre database of healthy controls for [123I]FP-CIT SPECT (ENC-DAT): age-related effects, gender differences and evaluation of different methods of analysis. Eur J Nucl Med Mol Imaging 2013;40:213-227.

52 Koch W, Unterrainer M, Xiong G, Bartenstein P, Diemling M, Varrone A, Dickson JC, Tossici-Bolt L, Sera T, Asenbaum S, Booij J, Kapucu OL, Kluge A, Ziebell M, Darcourt J, Nobili F, Pagani M, Hesse S, Vander Borght T, Van Laere K, Tatsch K, la Fougere C: Extrastriatal binding of $\left[{ }^{123} \mathrm{I}\right] \mathrm{FP}$-CIT in the thalamus and pons: gender and age dependencies assessed in a European multicentre database of healthy controls. Eur J Nucl Med Mol Imaging 2014;41:1938-1946.
Serotonin Transporters in Obesity and Insulin Resistance
Neuroendocrinology 2017;105:141-149 DOI: $10.1159 / 000450549$ 